\title{
Chromosome analysis of horse oocytes cultured in vitro*
}

\author{
WA King ${ }^{* *}$, M Desjardins ${ }^{2}, \mathrm{KP} \mathrm{Xu}^{1}$, D Bousquet ${ }^{3}$ \\ ${ }^{1}$ OVC, University of Guelph, Department of Biomedical Sciences; \\ ${ }^{2} O V C$, University of Guelph, Department of Clinical Studies; \\ Guelph, Ontario, N1G 2W1,Canada \\ ${ }^{3}$ Centre d'insémination artificielle du Québec \\ Inc, 3456 Sicotte St-Hyacinthe, Quebec, J2S 2M2 Canada
}

(Received 23 October 1989; accepted 22 February 1990)

\begin{abstract}
Summary - Oocytes collected from slaughtered mares of unknown reproductive history were cultured in modified Krebs Ringers bicarbonate supplemented with fetal calf serum (20\%) and fixed for chromosome analysis. To determine the time required for nuclear maturation, oocytes were fixed either after $12 \mathrm{~h}(n=21), 24 \mathrm{~h}(n=21), 48 \mathrm{~h}(n=20)$ and $60-96 \mathrm{~h}(n=12)$ or without culture $(n=30)$. In all $89 \%$ of those suitable for analysis, meiosis was resumed with $59 \%$ reaching second metaphase (MII) stage. In the majority of oocytes germinal vesicle breakdown occurred by the end of the lst $12 \mathrm{~h}$ of culture and MII was reached by $24 \mathrm{~h}$. To examine the chromosome features, an additional 113 oocytecumulus-complexes were cultured for $24 \mathrm{~h}$ before fixation. In all, 7 diakinesis/metaphase I (MI) and 36 MII spreads could be analyzed. Of the MII spreads, $5(13.8 \%)$ were found to be lacking chromosomes, 1 (2.7\%) had an excess of chromosomes and 1 (2.7\%) was diploid. Compensating for possible artifactual loss of chromosomes, the rate of non-disjunction or anaphase lagging was calculated to be $5.5 \%$ It was concluded that with respect to timing and chromosomal features, nuclear maturation of in vitro cultured oocytes in horses resembles that of other domestic animals.
\end{abstract}

meiosis / oocyte / nuclear-maturation / non-disjunction / horse

Résumé - Analyse des chromosomes d'ovocytes équins cultivés in vitro. Les ovocytes équins utilisés lors de cette étude furent prélevés chez des ovaires de juments ayant un statut reproductif inconnu. Ces ovocytes furent cultivés dans une solution de bicarbonate de Ringers modifiée, enrichie de $20 \%$ en sérum de veau faetal (SVF). La culture des ovocytes était achevée par la fixation de ceux-ci en vue d'une analyse chromosomique. Afin de déterminer le temps requis pour la maturation nucléaire, les ovocytes furent fixés après les périodes de culture suivantes: $0 h(n=30), 12 h(n=21), 24 h(n=21), 48 h(n=20)$ et 60 à $90 h(n=12)$. Les ovocytes fixés au temps $0 h$ servirent de groupe contrôle. Une reprise méiotique fut observée chez $89 \%$ des ovocytes étudiés et $59 \%$ atteignirent le stade de deuxième métaphase (MII). Dans la plupart des cas, la rupture de la vésicule germinale fut observée après $12 \mathrm{~h}$ de culture et la MII était atteinte avant $24 \mathrm{~h}$ de culture. Afin d'examiner l'aspect morphologique des chromosomes, 113 ovocytes entourés de leurs

* This study was carried out at the Animal Research and Reproduction Centre, Veterinary Medicine Faculty, University of Montreal, CP 5000, St-Hyacinthe, Québec, Canada, J2S 7C6

** Correspondence and reprints 
cellules du cumulus furent cultivés pour $24 h$ avant d'être fixés. On a pu ainsi identifier 7 diakinèse/métaphase I (MI) et 36 MII. Parmi les ovocytes qui atteignirent le stade MII, 5 (13,8\%) n'avaient pas de chromosomes présents, 1 (2,7\%) avait des chromosomes en surplus et 1 était diploïde. Après avoir compensé les pertes de chromosomes dues aux artéfacts, le taux de non-disjonction chromosomale ou d'anaphase tardive était de $5,5 \%$. Ainsi après culture des ovocytes équins in vitro, on peut conclure que la maturation nucléaire de ceux-ci est semblable à celle des autres espèces domestiques en ce qui concerne la synchronisation et l'apparence des chromosomes.

méïose / ovocyte / maturation nucléaire / non-disjonction / cheval

\section{INTRODUCTION}

It has been suggested that chromosome abnormalities are a significant factor accounting for infertility in the mare (Chandley et al, 1975). To-date, all reported cases of chromosomes abnormalities have been associated with fertility disturbances or congenital defects (Long, 1988). Most cases of aneuploidy, sex-chromosome (Trommerhausen Bowling et al, 1987; Long, 1988) and autosome (Power, 1987; Klunder et al, 1989) can be attributed to non-disjunction during female or male meiosis. The frequency of non-disjunction and irregular segregation during meiosis can be estimated by examining meiotic chromosomes at the second meiotic metaphase (MII). Several studies of male meiosis have been reported in the domestic species, including 1 in the domestic horse (Scott and Long, 1980). While involving only 8 stallions, the incidence of non-disjunction $(3.4 \%)$ was similar to that reported for other domestic males (Scott and Long, 1980). Meiosis in the female of the domestic species has also received considerable attention since it was first observed that meiosis resumes when oocytes are removed from immature follicles (Pincus and Enzmann, 1935) and that metaphase I and II preparations can be readily obtained by in vitro culture of oocytes collected from slaughtered females.

In the mare, very few descriptions of nuclear maturation (meiosis) of oocytes matured in vitro or in vivo have been reported (Webel et al, 1977; Fulka and Okolski, 1981; King et al, 1987). In fact, very little is known of the events leading to fertilization in this species. Here we report on the timing of nuclear maturation and the meiotic chromosomes of horse oocytes collected at slaughter and cultured in vitro. Preliminary observations from this study have been previously reported in abstract form (Desjardins et al, 1985).

\section{MATERIALS AND METHODS}

Ovaries were recovered from mares within $20 \mathrm{~min}$ of slaughter and were kept warm $\left(25^{\circ} \mathrm{C}-35^{\circ} \mathrm{C}\right)$ throughout the manipulation. The content of antral follicles $(>5 \mathrm{~mm}$ ) was aspirated into $20 \mathrm{cc}$ syringes through 18 gauge needles. The follicular fluid was transferred into heparinized petri-plates and oocyte-cumuluscomplexes located under a dissection microscope, transferred to sterile disposable 5 cc plastic tubes containing modified Krebs Ringers bicarbonate (KRb) solution (Fukui et al, 1982) and maintained at $30^{\circ} \mathrm{C}-37^{\circ} \mathrm{C}$ while being transported to the laboratory. Representative control oocytes ware selected at the slaughter house and transferred into cold PBS $\left(4^{\circ} \mathrm{C}\right)$. At the laboratory, the oocyte-cumulus complexes were transferred to fresh medium. Only oocytes with at least 1 layer of cumulus 
cells were used. Oocyte-cumulus complexes were then cultured in KRb enriched with $20 \%$ fetal calf serum. At the end of culture the cumulus cells were removed by treatment with a mixture of trypsin $(1 \mu \mathrm{g} / \mathrm{ml})$ and pronase $(1 \mu \mathrm{g} / \mathrm{ml})$ and hyaluronidase $(1 \mu \mathrm{g} / \mathrm{ml})$ and the oocytes were fixed individually on slides (King et al, 1979). Control oocyte-cumulus complexes were examined, their cumulus cells dispersed and they were fixed without culture. The slides were stained with acetoorcine and examined. The bivalents (MI) and univalents (MII) were counted and when possible, karyotypes were made.

The study was performed in 2 parts. In the first, oocytes were fixed after 12, 24, 48 and 60 to $96 \mathrm{~h}$ to determine the timing of nuclear maturation. In the second, oocytes were cultured for $24 \mathrm{~h}$ to obtain additional MII spreads for chromosome analysis.

\section{RESULTS}

\section{Part I}

In total 104 oocytes were collected, of which 74 were cultured before fixation and 30 were fixed without culture. Of those cultured, $62 \%(46 / 74)$ could be analyzed. Of these, $89 \%(41 / 46)$ had resumed meiosis and $59 \%(27 / 46)$ reached second metaphase. The meiotic stage after fixation in relation to the culture period is summarized in table I. Germinal vesicle breakdown (GVB) and the reappearance of the chromosomes (figs 1 and 2) was completed in $75 \%(9 / 12)$ of the analyzable oocytes after $12 \mathrm{~h}$ in culture and in all but $1(13 / 14)$ after $24 \mathrm{~h}$ culture. The resumption of meiosis was characterized by the reappearance of diffuse chromatin filaments with remnants of the nuclear membranes (fig 1) and nucleoli (fig 2). At MI (fig 3) and MII (fig 4) a modal value of 32 bivalents and univalents, respectively, was observed while the chromosomes generally resembled those of most mammals during meiosis. Occasionally, 2 metaphase spreads, the secondary oocyte metaphase and presumably the polar body metaphase, were observed in the same oocyte (fig 4).

Table I. Summary of the stage of nuclear maturation in oocytes fixed after various culture periods. * degenerated, no chromatin observed or chromatin present but stage of meiosis not recognizable.

\begin{tabular}{lcccccc}
\hline Culture time (h) & No oocytes & $G V$ & $\begin{array}{c}\text { diplotene/ } \\
\text { diakinesis }\end{array}$ & $M I$ & $M I I$ & $\begin{array}{c}\text { Not* } \\
\text { analyzable }\end{array}$ \\
\hline 0 & 30 & 1 & 7 & 3 & 4 & 15 \\
12 & 21 & 3 & 7 & 1 & 1 & 9 \\
24 & 21 & 1 & 0 & 3 & 10 & 7 \\
48 & 20 & 0 & 2 & 0 & 9 & 9 \\
$60-96$ & 12 & 1 & 1 & 0 & 7 & 3 \\
Total & 104 & 6 & 17 & 7 & 31 & 43 \\
\hline
\end{tabular}




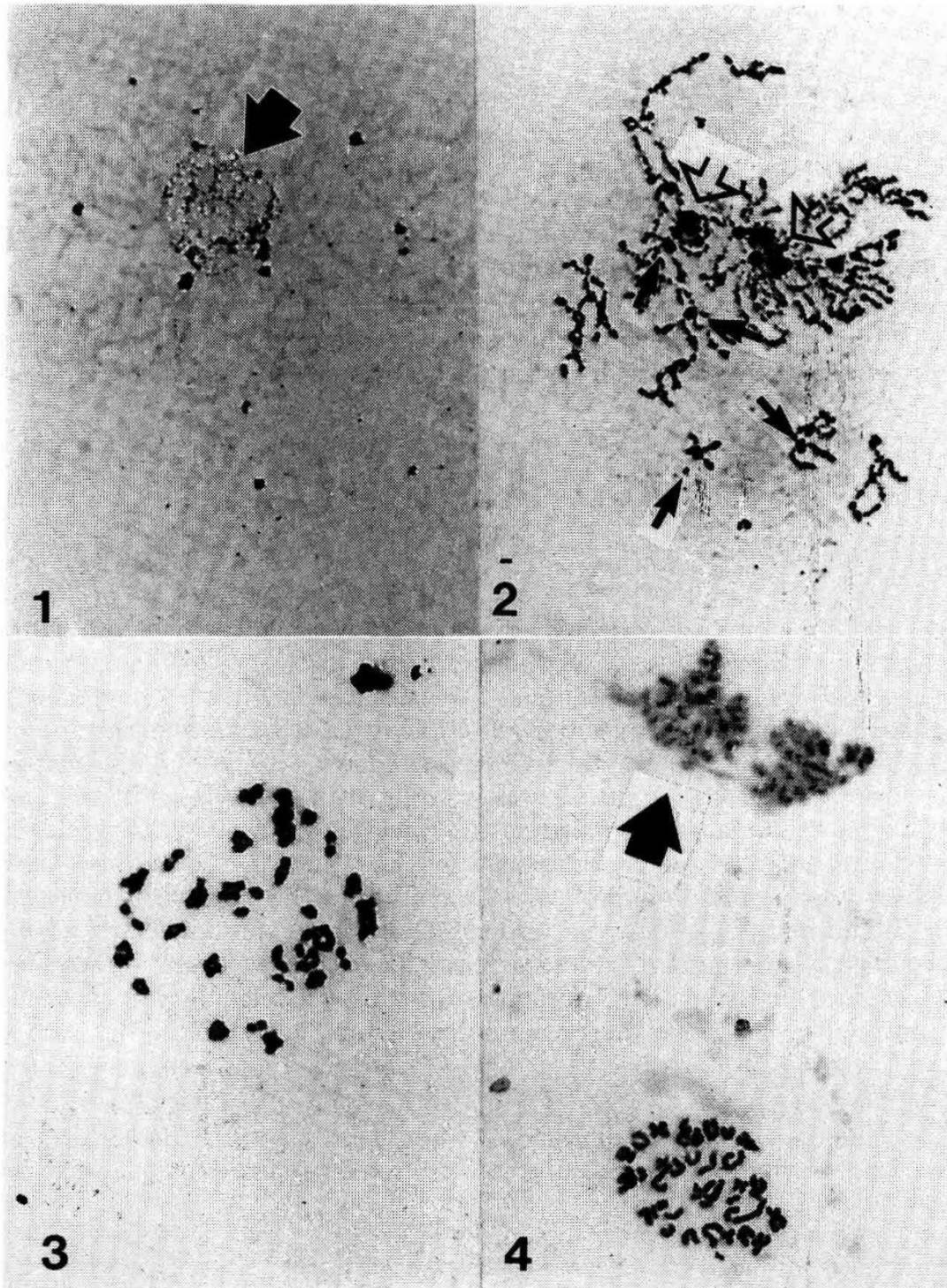

Fig 1-4. Photographs of chromosome preparation from horse oocytes cultured in vitro showing different stages of meiosis.

Fig 1. Germinal vesicle breakdown (GVB), note the remnants of nuclear envelope (arrows).

Fig 2. Early diakinesis, note the condensed chromatin in the centromeric regions of some chromosomes (arrows) and remnants of the nucleolus (open arrow).

Fig 3. First meiotic metaphase (MI).

Fig 4. Second meiotic metaphase (MII) and condensed chromatin of polar body (arrow). 


\section{Part II}

A total of 113 oocyte-cumulus-complexes were cultured for $24 \mathrm{~h}$. After fixation, $39 \%(44 / 113)$ could be analyzed. Of these, $93 \%(41 / 44)$ had resumed meiosis, $11 \%$ (5/44) were diplotene/early diakinesis stage, $18 \%$ (8/44) were diakinesis/MI stage and $68 \%(30 / 44)$ were MII stage. Two of the MII stage oocytes also presented presumptive polar body metaphase spreads.

By combining part I and II, a total of 14 diakinesis/MI were examined of which 5 had 32 bivalents, 2 had less than 32 and 7 were not of sufficent quality to be accurately counted. Sixty-one MII stage oocytes were examined, of these 29 had 32 univalents (haploid), 5 had less than 32 (hypohaploid), 1 had 33 (hyperhaploid), 1 had 64 (diploid) and 25 were not of sufficient quality to be counted. In addition to these, 5 metaphase spreads of presumptive polar bodies were examined, ( 1 with 32 univalents and 1 less than 32 univalents; 3 were uncountable).

The hyperhaploid metaphase contained 33 chromosomes which included an extra acrocentric chromosome. The spreads with 31 chromosomes were both missing a bi-armed chromosome while those with 30 or less chromosomes were missing both acrocentric and bi-armed chromosomes. The 5 hypohaploid spreads contained $31,31,30,29$, and 26 chromosomes respectively. The hypohaploid presumptive polarbody ( 25 chromosomes) was in the same oocyte as an MII spread with 31 chromosomes. The karyotype of a haploid, hypohaploid and hyperhaploid oocytes is shown in figures 5,6 and 7.

\section{DISCUSSION}

While female meiosis in the domestic horse has only been previously described using whole mount techniques, our observations on air-dried horse oocytes show that the stages of germinal vesicle breakdown, resumption and completion of meiosis resemble those of most domestic mammalian species (McGaughey and Chang, 1968; Jagiello et al, 1974; King et al, 1986; Madison, 1988). GVB in the majority of oocytes surrounded by at least 1 layer of cumulus cells was completed within $12 \mathrm{~h}$ of initiation of culture which is similar to the time required for GVB in cattle (Motlik et al, 1978) and sheep (Moor and Crosby, 1985; Madison, 1988). However, Fulka and Okolski (1981) reported that the time required for completion of in vitro oocyte nuclear maturation is longer in horses than in cattle or sheep more closely resembling that of pig (McGaughey and Polge, 1971). Our observations suggest, that under the conditions described here, the majority of oocytes which resume meiosis do reach MII within $24 \mathrm{~h}$ of initiation of culture, and in this respect nuclear maturation in the horse resembles that of cattle (King et al, 1986) and sheep (Madison, 1988). Some controversy concerning the stage of nuclear maturation of oocytes at ovulation exists in the literature; Hamilton and Day (1945) reported that oocytes are ovulated before MII while Van Niekerk and Gerneke (1966) suggested that MII occurs before ovulation. Working with air-dried oocytes King et al (1987) obvserved only MII stages in preovulatory oocytes while Webel et al (1977) observed both MI and MII stages in whole mount preparations of ovulated oocytes. The observation of 4 oocytes at MII stage in the uncultured groups in the present study are in agreement with the contention that oocytes can reach MII stage in the follicle. 


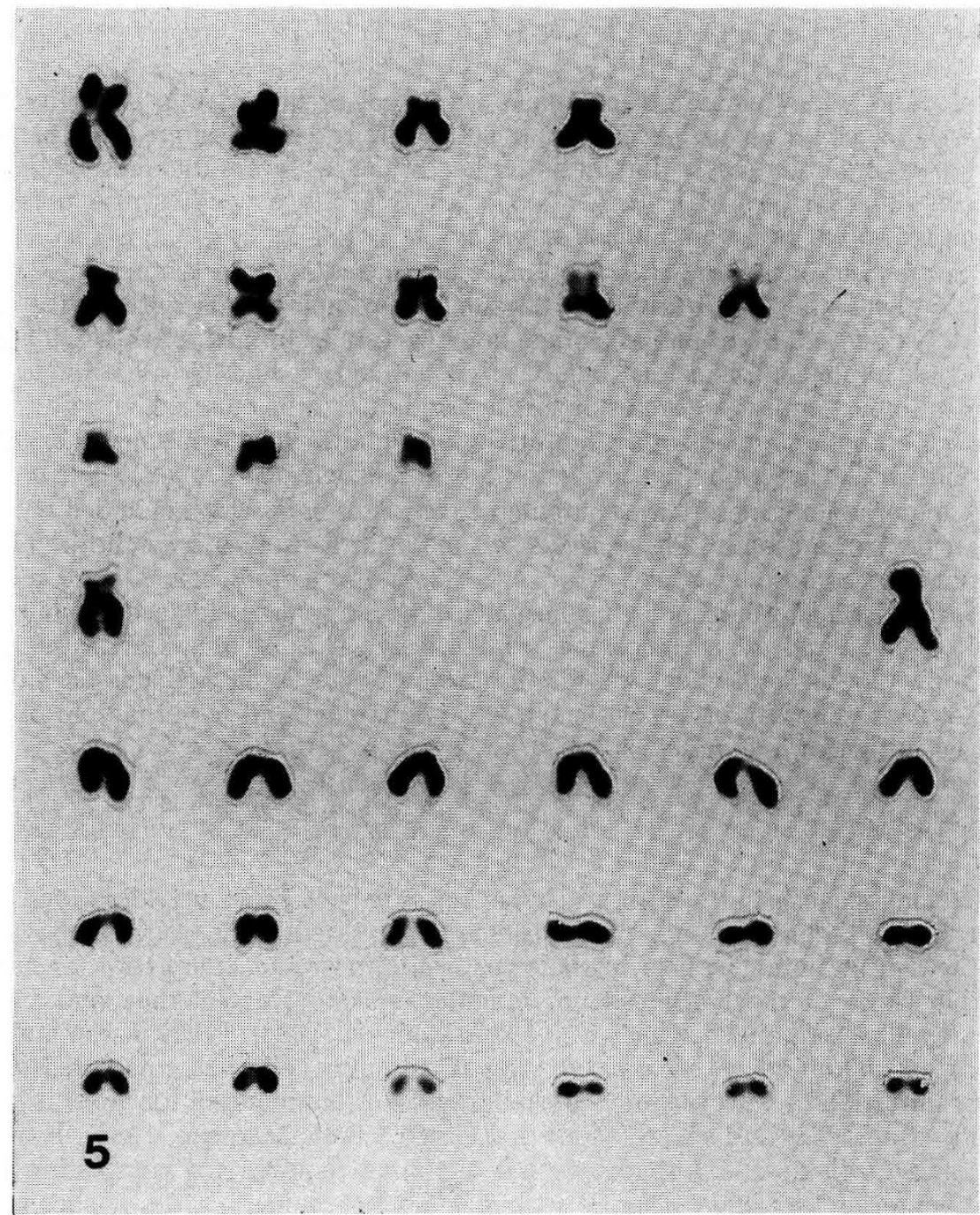

Fig 5-7. Karyotype from MII spreads. The chromosomes are arranged according to size and morphological groups although identification of individual chromosomes is not possible.

Fig 5. Karyotype of a haploid metaphase with 32 (18 acrocentrics and 14 biarmed) chromosomes.

Non-disjunction at the first meiotic division leads to hypohaploid or hyperhaploid MII spreads, theoretically in equal proportions, and fertilization of such oocytes would lead to aneuploid zygotes. Indeed, several cases of sex chromosome aneuploidy 63XO, 65XXX, 65XXY (Long, 1988) and 1 case of trisomy of autosome 23 (Klunder et al, 1989) have been reported in adult horses. Non-disjunction 


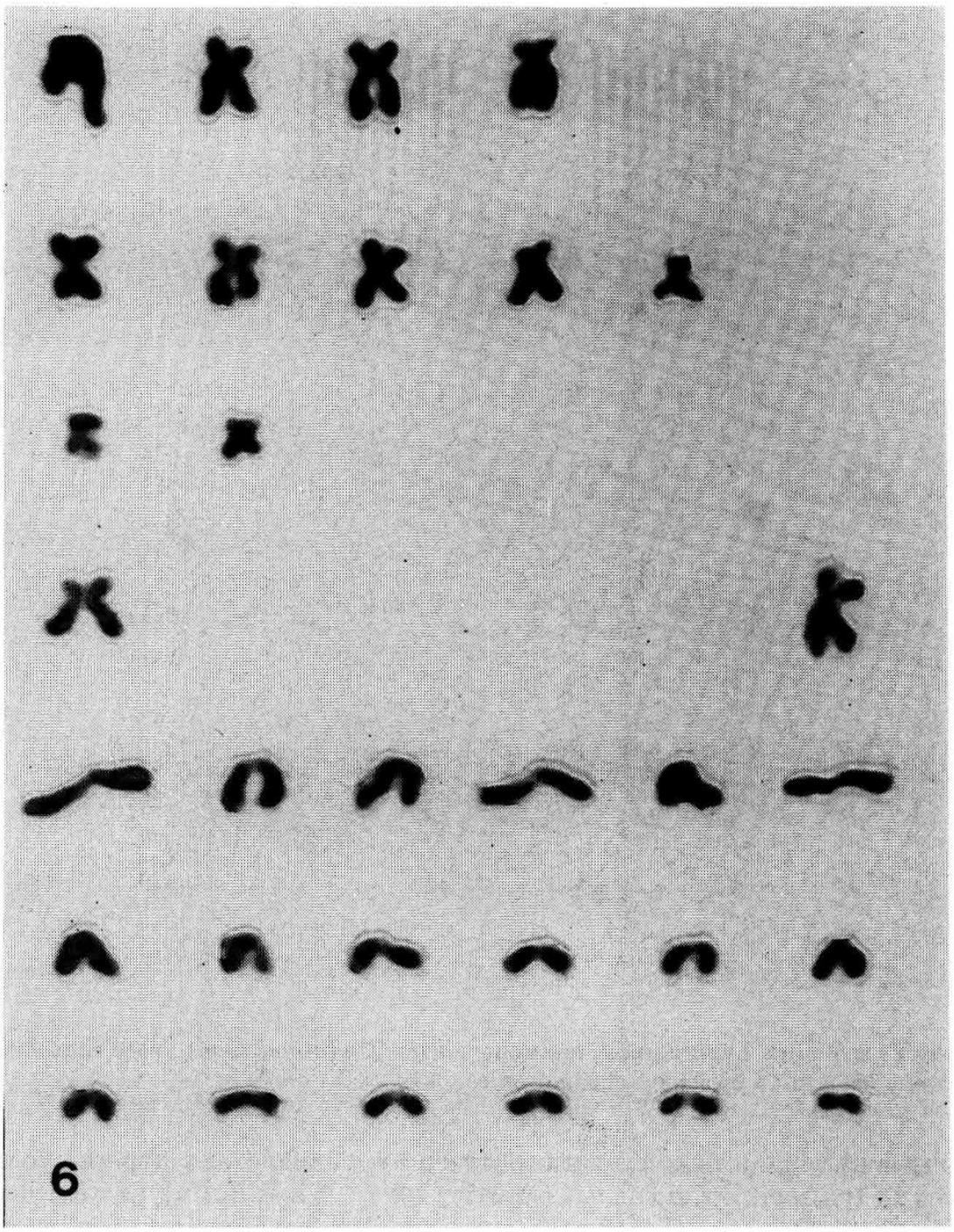

Fig 6. Karyotype of a hypohaploid metaphase with 31 chromosomes. Note that there are 18 acrocentrics and only 13 bi-armed chromosomes.

in the oocytes examined here was evidenced by the presence of hypohaploid (13.9\%) and hyperhaploid (2.7\%) MII spreads. The unequal ratio of hypohaploid to hyperhaploid (5:1) can be interpreted in at least 2 ways. Firstly, non-disjunction may have been accompanied by anaphase lagging so that there was a loss of chromosomes during meiosis rather than unequal distribution between oocyte and polar body, and secondly, during fixation chromosomes were artifactually lost. Support for the first interpretation comes from zona-free hamster oocytes penetrated by human sperm where an excess of hypohaploid oocyte complements 


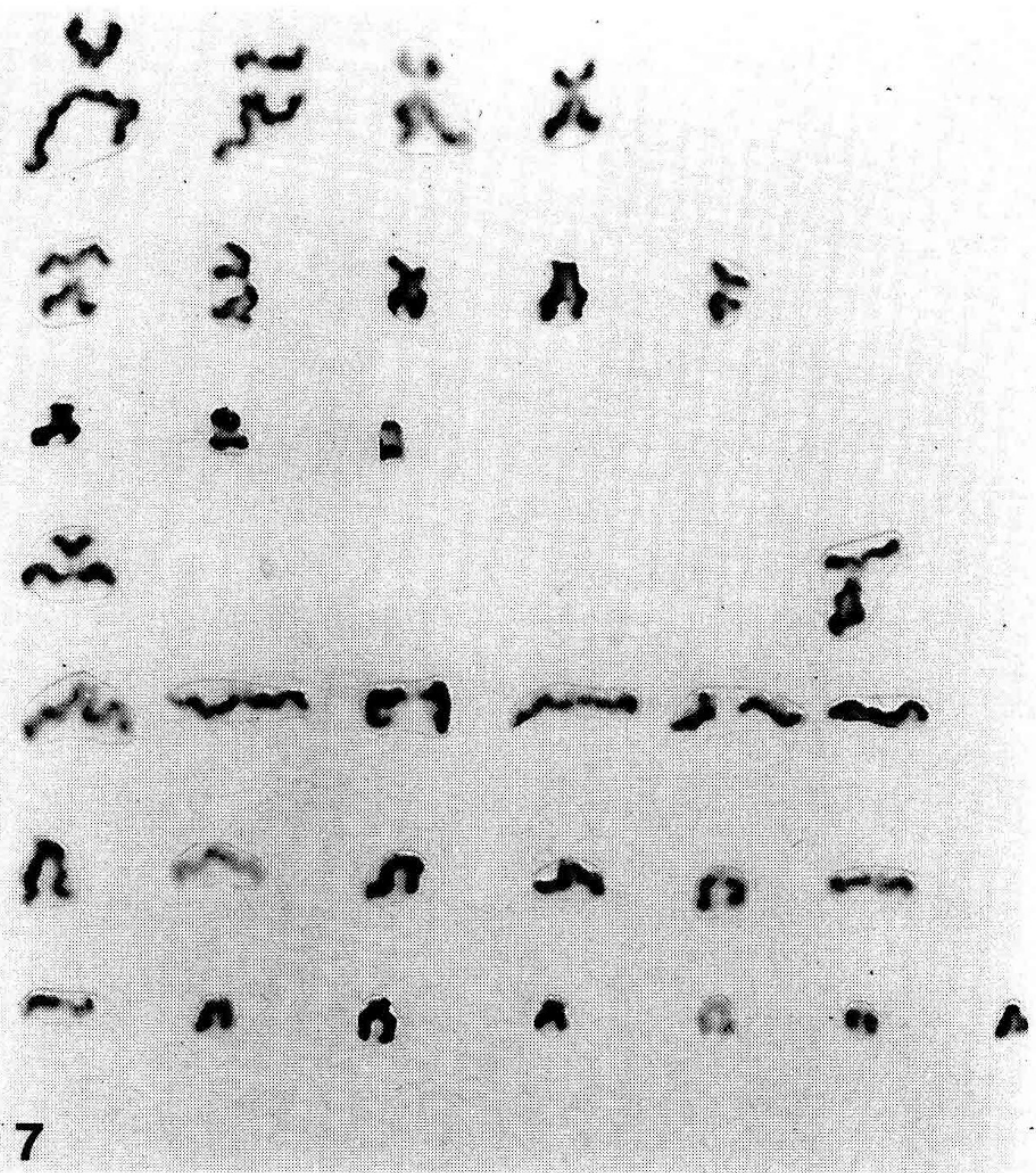

Fig 7. Karyotype of a hyperhaploid metaphase with 33 chromosomes. Note that there are 19 acrocentrics and 14 bi-armed chromosomes.

were observed while a near 1:1 ratio between hypohaploid and hyperhaploid was observed in the sperm complement (Martin, 1984). If loss during fixation had occurred it should have equally affected both complements. It might also be argued that since reported cases of X-chromosome monosomy outnumber X-chromosome trisomy in horses (Trommerhausen Bowling, 1987) there is a prevalence of chromosome loss during meiosis. However, the frequency of reports of $63 \mathrm{XO}$ mares may be related to the distinctive phenotypic features of these animals which motivates referral for karyotype analyses (Long, 1988). Observations on unselected populations of mares (Walker and Bruere, 1979; Long, 1988) and embryos (Romagnano et al, 1987), while limited, do not indicate high rates of non-disjunction or anaphase lagging during meiosis in vivo. Support for the second interpretation comes from the observation of an oocyte with MII and polar body spreads which were both hypohaploid. Non-disjunction would be expected to lead to a hyperhaploid and a hypohaploid metaphase while anaphase lagging would lead to a hypohaploid and 
a haploid metaphase. Also, oocytes with MI spreads with less than 32 bivalents indicate technical loss since it has been recognised that pre-meiotic non-disjunction or anaphase lagging of pairs of chromosomes is very rare (Hulten et al, 1985). If it is assumed that the majority of hypohaploids occur due to loss during fixation but that there is a 1:1 ratio between hypo - and hyperhaploid MII, a conservative estimation of non-disjunction would be $5.5 \%$ or twice the frequency of hyperhaploids. This rate is similar to the reported 3.4\% non-disjunction in the stallion (Scott and Long, 1980), $5.2 \%$ in men (Martin, 1984), $4 \%$ in human oocytes (Martin et al, 1986 ) and $3.3 \%$ in hamster oocytes (Martin, 1984).

From this study, it was concluded that oocyte-cumulus complexes collected from slaughtered mares are capable of nuclear maturation in vitro and provide suitable material for chromosomal analysis. The chromosomal features and the rate of nondisjunction and/or anaphase lagging during female meiosis are similar to those of other mammalian species.

\section{ACKNOWLEDGMENTS}

The financial support of NSERC is appreciated. We are grateful to the management and staff of Cofranca Inc and Dr Marcoux for valuable collaboration. We thank Ms M Blaquière, Ms S Lagacé and Ms D Pharoah for assistance with the preparation of this manuscript.

\section{REFERENCES}

Chandley AC, Fletcher J, Rossdale PD, Peace CK, Ricketts SW, McEnery RJ, Thorne JP, Short RV, Allan WE (1975) Chromosome abnormalities as a cause of infertility in mares. J Reprod Fertil (suppl) 35, 377-383

Desjardins M, King WA, Bousquet D (1985) In vitro maturation of horse oocytes. Theriogenology 23, 187 (abstr)

Fukui Y, Fukushima M, Terawak Y, Ono H (1982) Effects of gonadotrophins, steroids and culture media on bovine oocyte maturation in vitro. Theriogenology $18,161-175$

Fulka J Jr, Okoslki A (1981) Culture of horse oocytes in vitro. J Reprod Fertil 61, 213-215

Hamilton WJ, Day FT (1945) Cleavage stages of the ova of the horse, with notes of ovulation. $J$ Anat $79,127-130$

Hulten M, Saakallah N, Wallace BMN, Cockburn DJ (1985) Meiotic investigations of aneuploidy in the human. In: Aneuploidy Etiology and Mechanisms. Basic Life Sciences (Dellarco VL, Voytek PE, Hollander A, eds) Plenum Press, New York 36, 75-90

Jagiello GM, Miller WA, Ducayen MB, Lin SS (1974) Chiasma frequency and disjunctional behaviour of ewe and cow oocytes matured in vitro. Biol Reprod 10, 354-363

King WA, Bézard J, Bousquet D, Palmer E, Betteridge KJ (1987) The meiotic stage of preovulatory oocytes in mares. Genome 29, 679-682 
King WA, Bousquet D, Greve T, Goff AK (1986) Meiosis in bovine oocytes matured in vitro and in vivo. Acta Vet Scand 27, 267-279

King WA, Linares T, Gustavsson I, Bane A (1979) A method for preparing the chromosomes from bovine zygotes and blastocysts. Vet Sci Commun 3, 51-56

Klunder LR, McFeely RA, Beech J, McClune W (1989) Autosomal trisomy in a standardbred colt. Equine Vet $J 21,69-70$

Long SE (1988) Chromosome anomalies and infertility in the mare. Equine Vet $J$ 20, 89-93

McGaughey RW, Chang MC (1968) Meiosis of mouse eggs before and after sperm penetration. $J$ Exp Zool 170, 397-410

McGaughey RW, Polge C (1971) Cytogenetic analysis of pig oocytes matured in vitro. J Exp Zool 176, 383-396

Madison VJ (1988) Factors influencing in vitro maturation and fertilization of ovine oocytes. Doctoral Dissertation. Federal Swiss Institute of Technology Zurich

Martin RH (1984) Comparison of chromosomal abnormalities in hamster egg and human sperm pronuclei. Biol Reprod 31, 819-825

Martin RH, Mahadevan MM, Taylor PJ, Hildebrand K, Long-Simpson L, Peterson D, Yamamoto J, Fleetham J (1986) Chromosomal analysis of unfertilized human oocytes. J Reprod Fertil 78, 673-678

Moor RM, Crosby IM (1985) Temperature-induced abnormalities in sheep oocytes during maturation. $J$ Reprod Fertil 75, 467-473

Motlik J, Koefoed-Johnsen HH, Fulka J (1978) Breakdown of the germinal vesicle in bovine oocytes cultured in vitro. J Exp Zool 205, 377-384

Pincus G, Enzmann EV (1935) The comparative behaviour of mammalian eggs in vitro and in vivo. In: The activation of ovarian eggs. J Exp Med 62, 665-675

Power MM (1987) Equine half sibs with unbalanced X; 15 translocation or trisomy 28. Cytogenet Cell Genet 45, 163-168

Romagnano A, Richer CL, King WA, Betteridge KJ (1987) Analysis of Xchromosome inactivation in horse embryos. J Reprod Fertil (suppl) 35, 353-361

Scott IS, Long SE (1980) An examination of chromosomes in the stallion Equis caballus during meiosis. Cytogenet Cell Genet 26, 7-13

Trommerhausen Bowling A, Millon L, Huges JP (1987) An update of chromosomal abnormalities in mares. J Reprod Fertil (suppl) 35, 149-155

Van Niekerk CH, Gerneke WH (1966) Persistence and parthenogenetic cleavage of tubal ova in the mare. $J$ Vet Res 33, 195-232

Walker KS, Bruère AN (1979) XO condition in mares. New Zealand Vet J 27, 18-19 Webel SK, Franklin U, Harland B, Dziuk PJ (1977) Fertility ovulation and maturation of eggs in mares injected with HCG. $J$ Reprod Fertil 51, 337-341 